\title{
Transiciones de lo real
}

\section{Transformaciones políticas, estéticas y tecnológicas en el documental de Argentina, Chile y Uruguay}

\section{CECILIA LACRUZ}

ceci.lacruz@gmail.com - Grupo de Estudios Audiovisuales, Universidad de la República, Uruguay.

ORCID: https://orcid.org/0000-0002-8555-5886

CÓMO CITAR: Lacruz, C. (2021). Transiciones de lo real. Transformaciones políticas, estéticas y tecnológicas en el documental de Argentina, Chile y Uruguay. InMediaciones de la Comunicación, 16(1),219-228.DOI:http://doi.org.10.18861/ ic.2021.16.1.3105

Fecha de recepción: 4 de octubre de 2020

Fecha de aceptación: 15 de diciembre de 2020
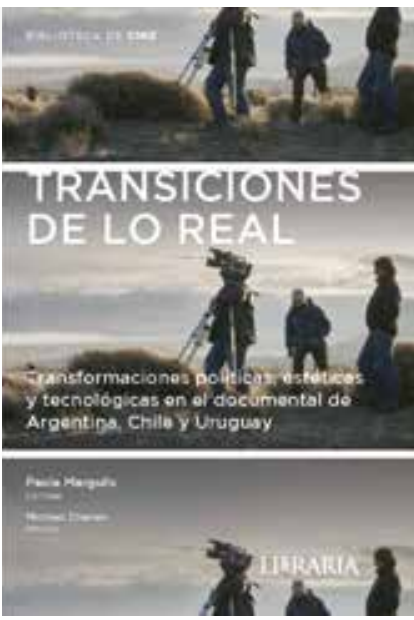

Margulis, P. (ed.) (2020). Transiciones de lo real. Transformaciones políticas, estéticas y tecnológicas en el documental de Argentina, Chile y Uruguay. Buenos Aires: Libraria.

\section{RESUMEN}

Tanto las dictaduras de Argentina (1976-1983), Uruguay(1973-1985)y Chile(1973-1990), como el retorno a la democracia de los tres países, presentaron rasgos y escenarios de contraste en relación con los procesos de justicia transicional sobre los crímenes de la dictadura, las políticas de memorias y las salidas negociadas. Ampliando la noción de transición a la que aluden estos procesos de restauración de los gobiernos democráticos, en el 2020 se publicó en Argentina el libro Transiciones de lo real. Transformaciones políticas, estéticas y tecnológicas en el documental de Argentina, Chile y Uruguay, editado por Paola Margulis. Esta reseña examina su propuesta y recorre los aspectos principales de los artículos publicados.

PALABRAS CLAVE: cine documental, cine latinoamericano, transiciones, video, archivo.

\section{ABSTRACT}

Both the dictatorships of Argentina (1976-1983), Uruguay (1973-1985) and Chile (1973-1990), as well as the return to democracy in the three countries, presented contrasting features and scenarios in relation to transitional justice processes on the crimes of the dictatorship, memory policies and negotiated solutions. Expanding on the notion of transition alluded to by these processes of restoration of democratic governments, in 2020 the book Transitions of the Real: Political, aesthetic and technological transformations in the documentary of Argentina, Chile and Uruguay, edited by Paola Margulis was published. This review examines its proposal and covers the main aspects of the published articles.

KEYWORDS: documentary cinema, Latin American cinema, transitions, video, archive. 


\section{RESUM0}

Tanto as ditaduras da Argentina (1976-1983), do Uruguai (1973-1985) e do Chile (1973-1990), bem como o retorno à democracia nos três países, apresentaram características e cenários contrastantes em relação aos processos de justiça transicional no crimes da ditadura, as políticas de memória e soluções negociadas. Ampliando a noção de transição a que aludem esses processos de restauração de governos democráticos, em 2020 foi publicado o livro Transiciones de lo real. Transformaciones politicas, estéticas y tecnológicas en el documental de Argentina, Chile y Uruguay [Transições do Real. Transformações políticas, estéticas e tecnológicas no documentário da Argentina, Chile e Uruguai]. Esta revisão examina sua proposta e percorre boa parte de seus artigos.

PALAVRAS - CHAVE: documentário, cinema latino-americano, transições, vídeo, arquivo. 


\section{TRANSICIONES BAJO LA LUPA: EL DOCUMENTAL POLÍTICO EN EL CONO SUR}

Tanto las dictaduras de Argentina (1976-1983), Uruguay (1973-1985) y Chile (1973-1990), como el retorno a la democracia de los tres países, presentaron rasgos y escenarios de contraste en relación con los procesos de justicia transicional sobre los crímenes de la dictadura, las políticas de memorias y las salidas negociadas. Ampliando la noción de transición a la que aluden estos procesos de restauración de los gobiernos democráticos, en el 2020 se publicó el libro Transiciones de lo real. Transformaciones políticas, estéticas y tecnológicas en el documental de Argentina, Chile y Uruguay. El mismo fue editado por la investigadora argentina Paola Margulis y tiene el propósito de pensar el documental político, un objeto de estudio de alta complejidad que invita a seguir reflexionando sobre los procesos de transición antes mencionados. El libro se organiza en cuatro secciones; tres de ellas dedicadas al estudio del documental político de cada caso específico: Argentina, Chile y Uruguay, y una última sección especializada en el archivo, el rescate y la puesta en disponibilidad de estas producciones.

Cada sección ofrece tres artículos escritos por académicos e investigadores. Una rápida mirada a sus breves biografías constata un aspecto que merece ser destacado: el libro reúne a una comunidad muy especializada y cuenta con un prólogo de Michael Chanan para inaugurar su lectura. Esto último no es un detalle menor ya que el autor encarna, de alguna manera, esa amplia noción de transición que esta publicación nos motiva a pensar. Es decir, su trayectoria evoca esa complejidad de la que nos hablan los trabajos reunidos por Margulis: el tránsito entre Europa y América Latina, el ir y venir entre el cine, la televisión, la realización y la academia, los cambios tecnológicos, los lazos intelectuales y políticos. Chanan mapea pedagógicamente los artículos y orienta a cualquier lector que se enfrente por primera vez con la temática del libro. Pero lo hace desde un lugar que podría pensarse como el de un protagonista-testigo que, notoriamente, expresa su compromiso intelectual y político con el material publicado.

Constituir a los documentales de las transiciones referidas en un objeto de estudio resulta una tarea compleja, ya sea porque algunas de estas obras se realizaron en diferentes continentes, porque los cambios tecnológicos del hacer fílmico, el video y el digital afectaron su circulación y el acceso que hoy tenemos a esos títulos, o porque todavía hoy se producen hallazgos de películas perdidas y hasta se finalizan documentales post-mortem. Al respecto, Margulis explica que:

La serie que caracterizamos como documentales de las transiciones no constituye un objeto dado ni resulta fácil de situar. Parte de la complejidad en la delimitación de este objeto reside en que una zona significativa de esta producción está compuesta por documentales realizados en distintas geografías, 
como consecuencia de viajes, exilios y retornos. La paulatina reunión de estas obras y la posibilidad de pensarlas como una serie son el resultado de largos procesos de búsqueda que se extienden por décadas, emprendidos no siempre en forma sistemática por académicos y distintas instituciones. (...) Se trata, en definitiva, de un cine que ha permanecido invisibilizado por décadas (p. 31).

Frente a esta producción, que en la introducción de Margulis se caracteriza como "dispersa”, "incompleta”, “dinámica”, la propuesta del libro es abandonar la rigidez conceptual o teórica que reduciría o limitaría el análisis del corpus documental disponible. Podríamos pensar esta convocatoria como un gesto saludable posible de imitar: el de reconocer que aquello que estudiamos se resiste muchas veces a ser pensado con un contorno nítido o con categorías que no logran dar cuenta de su compleja dinámica cultural, social, política o material. ¿Cómo incorporar al análisis de un film la clandestinidad de su rodaje y su distribución, las condiciones precarias y artesanales en las que fueron producidoso, por el contrario, el marco de una co-producción parala televisión europea como coartada para filmar otra película? ¿Cómo dar cuenta también, cuando abordamos estos títulos, de la coexistencia de tecnologías en una misma producción o de la dificultad del investigador para acceder a las obras? La categoría transiciones que los artículos ponen a funcionar en este libro es una respuesta posible. Como señala Margulis, "el estudio de las transiciones como categoría cultural y estética no ha tenido un peso equiparable al que este concepto posee en el marco de las ciencias políticas" (p. 28). En ese sentido, el plural del título - "transiciones"- alude a esa heterogeneidad de las dimensiones (políticas, culturales, tecnológicas, estéticas) que pueden pensarse a partir de esa noción de transición a la hora de analizar el documental político de los países del Cono Sur.

Por otra parte, la amplitud de la noción de transición que propone Margulis funciona como un estímulo para la tarea crítica, un aspecto no menor a la hora de incentivar la creatividad de la producción académica. Y en este libro hay ejemplos destacados de esa creatividad. El artículo "El eterno retorno de Raúl Ruiz: A TV Dante (Cantos IX-XIV) y La telenovela errante”, de José Miguel Palacios y Elizabeth Ramírez Soto, es uno de ellos. El trabajo parte del proyecto inconcluso de Ruiz, finalizado por Valeria Sarmiento en 2017, La telenovela errante. Aunque el acontecimiento de su recuperación ha sido revisado y valorado como un "eslabón perdido" de la obra del chileno, Palacios y Ramírez Soto lo conectan con su punto de partida original: A TV Dante (Cantos IX-XIV), un proyecto que Ruiz filmó en Chile durante los años 90 para una serie televisiva de Channel 4 (Reino Unido). Tan relevante es este vínculo que los autores proponen entender ambas obras como un díptico: lejos de ser una película excepcional, La telenovela errante "forma parte de un entramado ruiciano que atraviesa décadas y sobrepasa periodizaciones históricas” (p. 154). A lo largo del texto, Ramírez Soto y Palacios despliegan de manera atractiva la alta com- 
plejidad del documental transicional con el que trabajan y proponen conceptos más ajustados a las funciones históricas que revisan. Con esto, hacen eco de la necesidad de repensar el lenguaje y las terminologías académicas, un aspecto clave del espíritu del libro aquí reseñado. El primer término que proponen los autores surge como una crítica a la forma en la que se habla de la obra de Ruiz: para Palacios y Ramírez Soto, la insistencia en la idea del "retorno" y el "eslabón perdido" del relato dominante de La telenovela errante invisibiliza los incesantes regresos del director a lo largo de los años $80 \mathrm{y}$, en su lugar, los autores proponen hablar de un "retorno extendido" como un antídoto para deshacer "la cronología lineal del viaje del cineasta chileno en 1990 como el primer 'fin del exilio' en su trayectoria" (p. 139). Es decir: "Ruiz produce una temporalidad expandida del retorno, irreductible a fechas particulares y actos individuales de regreso a país natal" (Ibíd.). Otros dos términos originales de Palacios y Ramírez Soto para pensar la obra del cineasta chileno son: el de "teleasta", una palabra que imprime un vínculo con la televisión europea todavía no examinado en su trayectoria, y, por otro lado, el de "imágenes inestables", una idea que permite destacar "una porosidad entre ficción y no-ficción” (p. 133) y revertir la tendencia de analizar estas obras como ficciones.

Siguiendo con la sección dedicada a Chile y con el título “Transiciones en la mirada documental en Chile: Del cine de denuncia tras el golpe de Estado al video activista durante la dictadura (1973-1990)", el artículo de Antonio Traverso aborda el período abarcado entre el golpe de Estado y el fin dela dictadura con el propósito de pensar los cambios de soportes y métodos utilizados por los documentalistas chilenos. El autor revisita uno de los títulos más conocidos de la filmografía chilena, La batalla de Chile, de Patricio Guzmán (1975-1979), para luego atender una serie de títulos menos explorados: un conjunto de documentales realizados por cineastas chilenos que filmaron clandestinamentey un corpus de películas realizadas durante la dictadura por distintos colectivos audiovisuales. En esta última parte, Traverso recupera, entre otros títulos, dos obras del colectivo Cámara en Mano: Orgasmo Callejero (1987) y One player (1987), la experiencia de televisión alternativa de Ictus TV yla Red de Video Popular de Ictus, y realizaciones de la productora independiente Grupo Proceso.

En el artículo que cierra la sección del caso chileno, "Atravesando géneros, tiempos y memorias: Tránsitos y transiciones en el cine de Ignacio de Agüero", de Valeria de los Ríos Escobar y Catalina Donoso Pinto, las autoras vuelven a pensar la obra del documentalista Ignacio Agüero, a quien antes le dedicaron el libro El cine de Ignacio Agüero. El documental como la lectura de un espacio (2015), pero esta vez con el propósito de trazar dos dimensiones dela transición, una más específicamente política y otra más vinculada a la cultura y el cine. Las autoras analizan la forma en que Sueños de hielo (1993) y GAM (2011) “desafían las narrativas consensuadas sobre la transición política chilena como proceso exitoso" (p. 194), mientras que Como me da la gana (1985) y Como me da la gana 
2 (2016) marcan "el paso hacia el cine como campo expandido" (p. 195).

Por su parte, en el primer artículo de la sección dedicada a Uruguay, titulado "Mario Handler y un tríptico cinematográfico sin hipótesis", Federico Beltramelli examina la obra de uno de los más reconocidos documentalistas uruguayos y propone analizarla como un tríptico de tres etapas. La primera correspondería al período de los años 60 (1964-1972), la segunda al exilio venezolano (1973-1978) y la tercera se iniciaría en 1999 hasta la actualidad. Beltramelli deja a un lado el trabajo de Handler durante el exilio para centrarse en el período inaugural de los sesenta y en la actualidad, dos momentos que le permiten trazar temáticas comunes entre Carlos, cine-retrato de un "caminante" en Montevideo (1965) y el documental "más visto del cine uruguayo de todoslos tiempos" (p. 218), Aparte (2003); entre Elecciones (1967) y El voto que el alma pronuncia (2011); o entre 1969: el problema de la carne (1969) y el film que el director realizó con 81 años, Columnas Quebradas (2015). Mientras traza un ir y venir de un título a otro, Beltramelli narra el momento en el que Handler se integra a la Licenciatura en Ciencias de la Comunicación de la Universidad de la República (UdelaR) e inicia su etapa experimental con el video, lo cual es articulado con la docencia y las intervenciones en torno a la tecnología.

En el segundo artículo sobre el caso uruguayo, "Documentales uruguayos de los ochenta: La resistencia entre el super-8 y el video", Julieta Keldjian y Beatriz Tadeo Fuica proponen un recorrido por la producción uruguaya de los años 80 pensando en una doble transición: la de la dictadura a la democracia y la del super-8 (el formato pensado para uso doméstico que utiliza una película de $8 \mathrm{~mm}$ ) y el video. No es la primera vez que Keldjian y Tadeo Fuica discuten temáticas relacionadas con el cine de este período en Uruguay, y en la bibliografía de este capítulo puede verificarse la reflexión sistemática sobre esta filmografía que han llevado a cabo las autoras. En este artículo se detienen en el colectivo de realización audiovisual Grupo Hacedor, que funcionó en los años 80 y 90, a partir de un grupo de teatro que experimentaba con el super- 8 (Comuniteatrocine) y otro espacio cooperativo de cine super-8 llamado CINECO. En ese marco, Keldjian y Tadeo Fuica profundizan en la experiencia del cortometraje 1 de mayo de 1983 (1983) y Los ojos en la nuca (1988). Este último fue filmado en super-8, pero luego producido en video, e incluye imágenes de la liberación de los presos políticos del Penal de Libertad y testimonios de familiares de desaparecidos, así como de integrantes (rehenes) del Movimiento de Liberación Nacional Tupamaros MLN-T. Como señalan las autoras, el caso del Grupo Hacedor muestra cómo

la relación entre materialidad, registro, procesamiento, edición y distribución ha estado sujeta a una tensión dinámica que no solo ha posibilitado la existencia de una filmografía amateur y precaria -en términos formales y estéticos- sino que también ha definido una práctica documental híbrida entre el cine y el video, caracterizada por la ubicuidad y a espontaneidad (p. 238). 
Cabe destacar que, en el inicio del artículo, las autoras también recuperan y vinculan el escenario del super-8, single 8 y el video con la aparición de la Coordinadora Uruguaya de Ciney Video (CUCV) fundada en 1984, una agrupación gremial que surgió con el propósito de luchar por una cultura cinematográfica propia, vinculada a su realidad histórica.

En el tercer artículo sobre el documental político en Uruguay, "Documentales y transmisión intergeneracional del pasado reciente: Entre la denuncia y la reflexión", Mariana Achugar se centra en dos obras singulares: Por esos ojos, de Gonzalo Arijón y Virginia Martínez (1997) y Trazosfamiliares, de José Pedro Charlo (2017). La autora pone atención en la experiencia infantil durante la dictadura uruguaya, y toma a dos generaciones como eje de su análisis a la hora de pensar las transmisiones de memoria social. Para este propósito, la elección de estos dos documentales resulta muy acertada: ambos muestran el caso paradigmático de Mariana Zaffaroni, bien conocido en el Río de la Plata, secuestrada junto con sus padres en Buenos Aires en 1976 y localizada por las Abuelas de Plaza de Mayo, en 1983, aunque su identidad fue recién restituida en 1993. ¿Quién no recuerda el rostro de bebé de Mariana, que, como dice la autora, se convirtió en un símbolo de los niños robados por la dictadura? En esa línea, Por esos ojos muestra el momento en el que ella rechaza su identidad, mientras que en Trazos Familiares nos acercamos a una Mariana que inició el proceso de aceptación de su familia biológica. Como dice la autora, tanto Martínez como Charlo son dos realizadores "emblemáticos del cine documental uruguayo en torno a la memoria traumática" (p. 259), y este artículo los reúne de forma productiva para analizar el pasado reciente. En su análisis, Achugar se ocupa de pensar los contextos históricos de producción de cada documental en relación con las políticas de memoria y señala, también, la transición en los modos de narrar el pasado reciente, del dominio más bien expositivo al giro subjetivo que permea las narrativas más contemporáneas.

Por su parte, en el primer artículo referido al caso de Argentina, "Imágenes distantes de un pasado reciente: Archivo, ficción y testimonio en los documentales de la recuperación democrática", Gustavo Aprea analiza un corpus documental del período 1983-1989 que le sirve para poner atención en el valor testimonial del material de archivo, en las formas de su apropiación, en el uso del testimonio, así como en el recurso menos habitual de la reconstrucción de los acontecimientos en el documental de aquellos años. Dentro del mismo período se inscribe el segundo artículo escrito por Javier Campo, "Testimoniar en tierra arrasada. El cine documental político argentino entre 1983 y 1989”. En este trabajo, el autor plantea un análisis comparativo de los documentales que denunciaron la desaparición de personas, destacando el dominio de las narrativas democrático-humanitarias que los caracterizaron. Campo piensa en estos testimonios no solamente para señalar las omisiones que dichos tes- 
timonios exponen acerca de la trayectoria militante de los desaparecidos y su lucha revolucionaria anterior, sino para articularlos a una estética, a una forma en la que el documental político los pone en escena, ya sea en relación con un estilo observacional -en el cual el protagonista dialoga con otro sujeto-, como también por el modo en que se inserta la voz en relación con el cuerpo o como efecto de la ausencia de cortes en la edición.

Por su parte, el artículo de Margulis que cierra la sección dedicada al caso argentino, "Expectativas en transición: El tratamiento fílmico de las leyes de Punto Final, Obediencia Debida ylos indultos en el documental argentino dela restauración democrática", se pregunta acerca de cómo los documentales mostraron el desencanto que generaron las leyes y los decretos que restringieron el castigo a los culpables por los crímenes de la última dictadura. Como explica la autora, las categorías de "cine del exilio" o la de "cine nacional" marginaron, de alguna manera, el corpus del que se ocupa el trabajo de Margulis: se trata de títulos dirigidos por argentinos que estaban en el exilio o residían en el extranjero, como las películas de Jorge Denti No al Punto Final (1986) y Entre el cielo y la tierra (1986), o El beso del olvido, de Eduardo Mignogna (1991), entre otros materiales. Margulis destaca "un sentimiento generalizado de decepción como clima de época” (p. 124) y explora, en estos films, la presencia de un desencanto que, además de referirse a las expectativas en relación con la justicia, apunta también a la desigualdad económico-social, el giro neoliberal, la corrupción y los “problemas irresueltos de la transición democrática” (p. 109).

En la sección final del libro dedicada, como ya mencionamos, al archivo, el rescate y la puesta en disponibilidad de este tipo de producciones audiovisuales, Sebastián Vidal Valenzuela trabaja sobre los archivos de arte y videoarte para el caso chileno, Mariel Balás y Tadeo Fuica abordan el Centro de Medios Audiovisuales (CEMA) de Uruguay y Pablo Gullino explora un corpus marcado por un rasgo común: la representación de la Guerra de Malvinas por medio de tecnologías generadas por computadora. Artículos que, para concluir, terminan de completar un libro que es una contribución relevante para el campo de estudios del cine documental latinoamericano y que propone miradas novedosas sobre un corpus de difícil acceso -en su mayor parte-. También es una forma de continuar preguntándonos acerca de cómo analizar y recuperar las prácticas cinematográficas, las colaboraciones existentes, las formas de filmar y de distribuir lo producido y el lugar de las tecnologías en marcos históricos transicionales que nos hablan de las transformaciones culturales, sociales, económicas y políticas de la región.

\section{REFERENCIAS}

delos RíosEscobar, V.\&Donoso Pinto, C.(2015).Elcine de Ignacio Agüero.Eldocumental como la lectura de un espacio. Santiago de Chile: Cuarto propio. 


\section{MATERIAL AUDIOVISUAL CITADO}

Grupo Hacedor (1983). 1 de mayo de 1983. Uruguay: Grupo Hacedor.

Grupo Hacedor (1988). Los ojos en la nuca. Uruguay: Grupo Hacedor.

Arijón, G. \& Martínez, V. (1997). Por esos ojos. Francia-Uruguay: Point du Jour France 2-télé Europe y Tevé Ciudad.

Cámara en Mano (1987). One player. Chile: Cámara en Mano.

Cámara en Mano (1987). Orgasmo Callejero. Chile: Cámara en Mano.

Charlo, J. P. (2017). Trazos familiares. Alemania-España-Uruguay: Guazú Media.

Agüero, I. (1985). Como me da la gana. Chile: Ignacio Agüero.

Agüero, I. (1993). Sueños de hielo. Chile: Ignacio Agüero y Andrés Racz.

Agüero, I. (2011). GAM. Chile: Lupe Films.

Agüero, I. (2016). Como me da la gana 2. Chile: Ignacio Agüero \& Asociado.

Denti, J. (1986) Entre el cielo y la tierra. México / Argentina: TVAL Producciones.

Denti, J. (1986). No al Punto Final. México-Argentina: TVAL Producciones.

Guzmán, P. (1975-1979). La batalla de Chile. Chile-Cuba-Francia: Equipo Tercer Año e Instituto Cubano del Arte e Industrias Cinematográficas.

Handler, M. (1965). Carlos, cine-retrato de un "caminante" en Montevideo. Uruguay: Instituto de Cinematografía de la Universidad de la República.

Handler, M \& Ulive, U. (1967). Elecciones. Uruguay: Instituto de Cinematografía de la Universidad de la República.

Handler, M. (1969). 1969: el problema de la carne. Uruguay: Departamento de Cine de Marcha

Handler, M. (2003). Aparte. Uruguay: Mario Handler.

Handler, M. (2011). El voto que el alma pronuncia. Uruguay: Mario Handler.

Handler, M. (2015). Columnas Quebradas. Uruguay: Doce Gatos S.L. y Karin Handler.

Handler, M. (2007). Decile a Mario que no vuelva. Uruguay: Doce Gatos S.L.

Mignogna, E. (1991). El beso del olvido. Argentina: Videoflor.

Ruiz, R. (1990). A TVDante (Cantos IX-XIV). Reino Unido: Artifax, CAL Videographics Ltd., Channel 4 Television Corporation, Dante B.V., Elsevier, Vendex Film Beheer, RM Associates y Vrijzinning Protestantse Radio Omroep. 
Ruiz, R. \& Sarmiento, V. (1990-2017). La telenovela errante. Chile: Poetastros \& RR Producciones.

${ }^{*}$ Contribución: $100 \%$ de la autora.

* Nota: el Comité Editorial de la revista aprobó la publicación de la reseña.

\section{(c) BY}

Artículo publicado en acceso abierto bajo la Licencia Creative Commons - Attribution 4.0 International (CC BY 4.0).

\section{IDENTIFICACIÓN DE LAAUTORA}

Cecilia Lacruz. Doctora (Cand.) en Ciencias Sociales, Universidad de Buenos Aires (Argentina). M.Phil. en Latin American Studies, Universidad de Cambridge (Reino Unido). MA en Film Studies, University College Dublin (Irlanda). Licenciada en Comunicación orientación Audiovisual, Universidad ORT Uruguay. Co-fundadora e integrante del Grupo de Estudios Audiovisuales (GEstA) y Gr. 2, Facultad de Humanidades y Ciencias de la Educación, Universidad de la República (Uruguay). Investigadora, Agencia Nacional de Investigación e Innovación (ANII). Colaboró en volúmenes colectivos con los artículos: La pantalla presa en Libertad (2015), Uruguay: la comezón por el intercambio (2016) y Rostros, voces, miradas: notas sobre el pueblo en el cine documental uruguayo de los años sesenta (2018). 


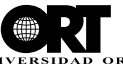

UNIVERSIDAD OR 